\title{
Ocular findings in thrombotic thrombocytopenic purpura (Moschcowitz's disease)
}

\author{
S. P. B. PERGIVAL \\ From the Area Department of Ophthalmology, The Eye, Ear and Throat Hospital, Shrewsbury
}

Thrombotic thrombocytopenic purpura is a disease of unknown aetiology which affects children or adults of any age but especially young adult females, and which usually proves fatal within a few weeks. The condition was first described by Moschcowitz (1925). Since then various suggestions for terminology have been made, and in Great Britain the more popular names are thrombotic thrombocytopenic purpura (which is now in nearly universal use in the United States of America), Moschcowitz's disease, and (thrombotic) microangiopathic haemolytic anaemia. As the synonyms are unwieldy yet even so do not describe all the characteristic pathological features, and as one should not advocate the use of initials such as TTP, it has been decided in this paper to continue with the simple eponym of Moschcowitz's disease.

The disease is characterized by

(i) Widespread plugging of small arterioles and capillaries with fibrinous material,

(ii) Fluctuating neurological signs which may vary from transient pareses to deep coma,

(iii) Acute haemolytic anaemia,

(iv) Thrombocytopenic purpura. It is often also accompanied by fever and renal failure. Should diagnosis be achieved early enough, the treatment (paradoxically) is with heparin (Dacie, 1967; Allanby, Huntsman, and Sacker, I966; Brain, Baker, McBride, Rubenberg, and Dacie, 1968). Death usually ensues from cerebral haemorrhage, renal failure, or pulmonary oedema.

As visual disturbances are common in Moschcowitz's disease, it is pertinent that ophthalmologists should be aware of their nature, especially as the key to treatment is early diagnosis. This depends to a great extent on the characteristic group of clinical findings since tissue biopsy is often negative. This paper provides the first ophthalmic pathological report on the disease and also a review of the ocular manifestations.

\section{Case report}

A housewife aged 19 had been delivered of her first-born child on August 26, 1968. The pregnancy had been without complication. She later suffered from progressive tiredness and on October I 7 was re-admitted to hospital. 


\section{Examination}

She appeared pale, slightly jaundiced, and with hepatomegaly and a purpuric rash over her arms, neck, and legs.

\section{Laboratory investigations}

Hb $5.9 \mathrm{~g}$./100 ml. falling later to $4.4 \mathrm{~g}$./100 ml.; leucocytes I 1,000; ESR $32 \mathrm{~mm}$./1 hr; blood film showed numerous spherocytes and reduced platelets; serum bilirubin $1 \cdot 7 \mathrm{mg} / 100 \mathrm{ml}$. (direct van den Bergh 0.4 mg./10o ml.).

Sternal puncture revealed an extremely active pleomorphic normal marrow. Serum electrolytes, proteins, vitamin $\mathrm{B}_{12}$, folate, SGOT, and alkaline phosphatase, and the prothrombin time were all within normal limits.

Chest $x$ ray was normal and abdominal $x$ ray confirmed marked hepatic enlargement.

Repeated examination of midstream specimens of urine revealed albuminuria, a deposit showing red blood cells and occasional hyaline casts, and a profuse growth of $E$. coli.

Serological tests for glandular fever, rheumatoid arthritis, lupus erythematosus, leptospirosis, and syphilis were negative. The Coombs test was weakly positive.

\section{Therapy}

She was treated with multiple blood transfusions, with antibiotics for the urinary infection, and with prednisolone beginning at $60 \mathrm{mg}$. daily. She was discharged on November 12, 1968, with the diagnosis of acquired haemolytic anaemia with progressive thrombocytopenia.

\section{Progress}

On November 18 she was readmitted with further purpuric haemorrhages, abdominal pain, and

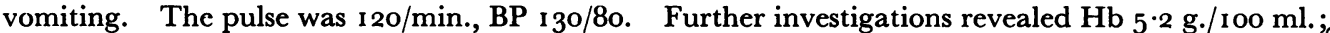
leucocytes I5,000; platelets 50,000; erythrocyte sedimentation rate $25 \mathrm{~mm}$./ I hr; blood urea $85 \mathrm{mg}$. $100 \mathrm{ml}$. After further transfusions the blood pressure rose transiently to $210 / 100$. She remained afebrile. On November 24 the BP rose transiently to $210 / 120$, and haematuria and melaena developed.

\section{Termination}

The patient was restless and complained of visual blurring; 2 days later she developed a left hemiplegia and became deeply comatose until her death on November 28 , 1968, only 3 months after the birth of her child.

Ophthalmic examination on November 26, 1968

The visual acuity was unobtainable owing to the patient's drowsy state; the ocular movements were wandering and involuntary; the lids were oedematous; the pupillary reactions were normal and the media clear. The fundi (on mydriasis) were of good colour; the discs and posterior poles appeared normal and there was no evidence of anaemic or thrombocytopenic retinopathy; bilateral retinal detachment was present with ballooning forward of the retina in the left infero-nasal quadrant and the right infero-temporal quadrant; the retinal vessels appeared normal and there was no evidence of a retinal hole, tear, or dialysis. The patient was lying with her head turned to the right.

Post mortem examination

Traces of subarachnoid haemorrhage were present over the surfaces of the right cerebral hemisphere; scattered small haemorrhages were present in the white matter of the brain, especially in the left basal ganglia, pons, and the left occipital pole. There was a pericardial effusion; both lungs were moderately oedematous, and haemorrhages were present in the walls and mucosa of the alimentary tract and urinary bladder. The spleen 
was congested, and infarcted at one point. The cerebral, coronary, and other large arteries were healthy.

Microscopically, the capillaries, venules, and arterioles especially of the adrenal, myocardium, pancreas, liver, and kidney showed a striking occlusive slightly granular fibrinous material, but without inflammatory changes in the vessel walls.

The post mortem diagnosis was thrombotic thrombocytopenic purpura with terminal cerebral haemorrhages.

\section{Ocular pathology}

Microscopic section of the eye showed the corneal epithelium to be loose, but Bowman's layer, the stroma, Descemet's membrane, and the filtration angle were within normal limits. There was a mild chronic inflammation in the iris, and the ciliary processes showed some sclerosis. The retina had undergone a shallow detachment (Fig. I).

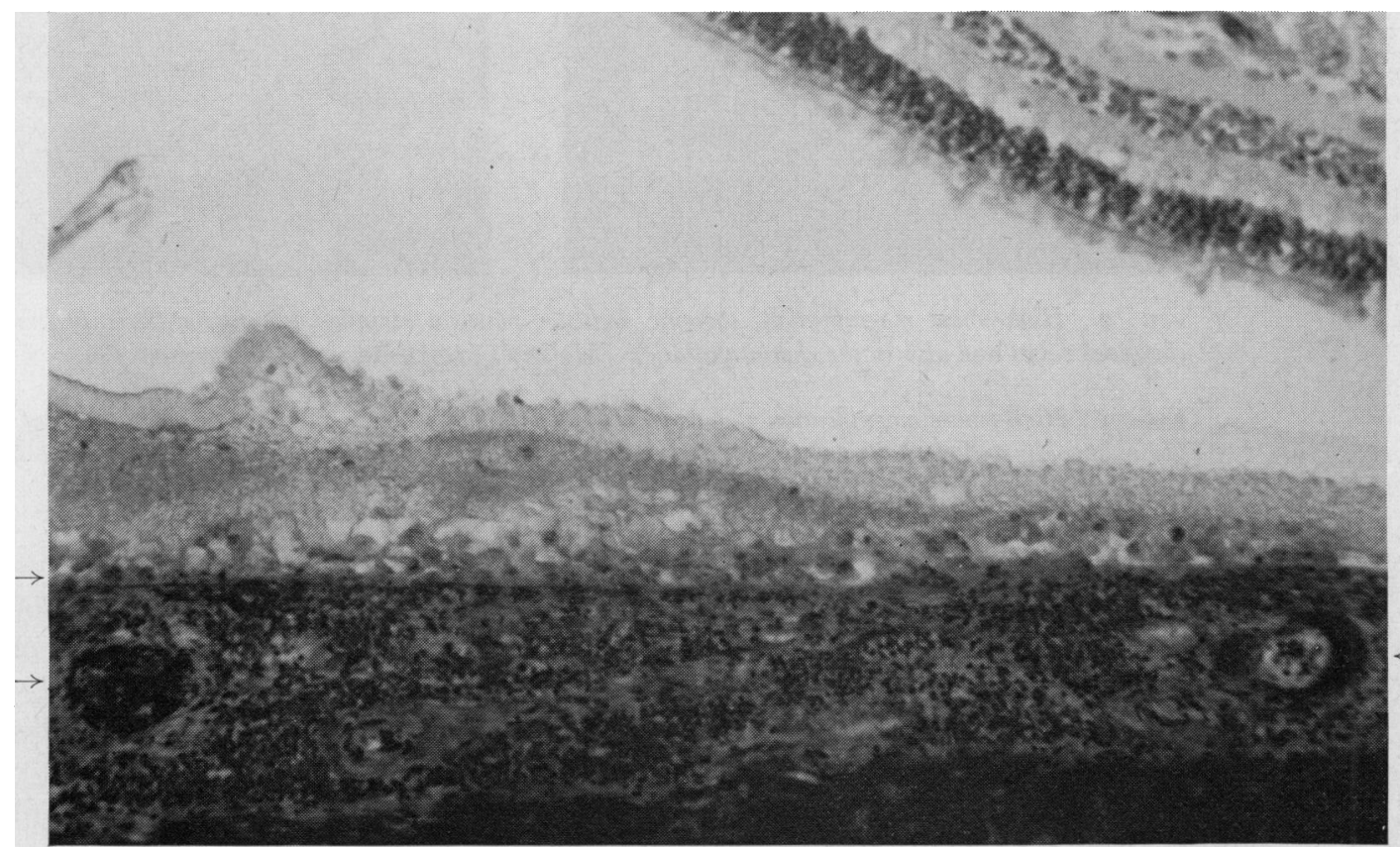

FIG. I Choroid, showing haemorrhagic effusions, vessels containing occlusive material (arrows), and retinal detachment. Mallory's phosphotungstic acid haematoxylin. $\quad \times 150$

The posterior choroid showed haemorrhagic effusions and some choroidal arteries had thickened walls. Posteriorly some choroidal vessels were obliterated completely or partially by a material which stained for fibrin (Figs 2 and 3, overleaf). This microangiopathy could not be demonstrated elsewhere in the globe. The retinal vessels and optic nerve appeared normal, and no significant change was found in the lens.

\section{Discussion}

The aetiology of the disease is not known: an autoimmune process is a possibility, but no specific immunoglobulins have ever been detected and the Coombs test is usually negative. Currently it is thought that the primary defect lies in the vascular endothelium, and is of 

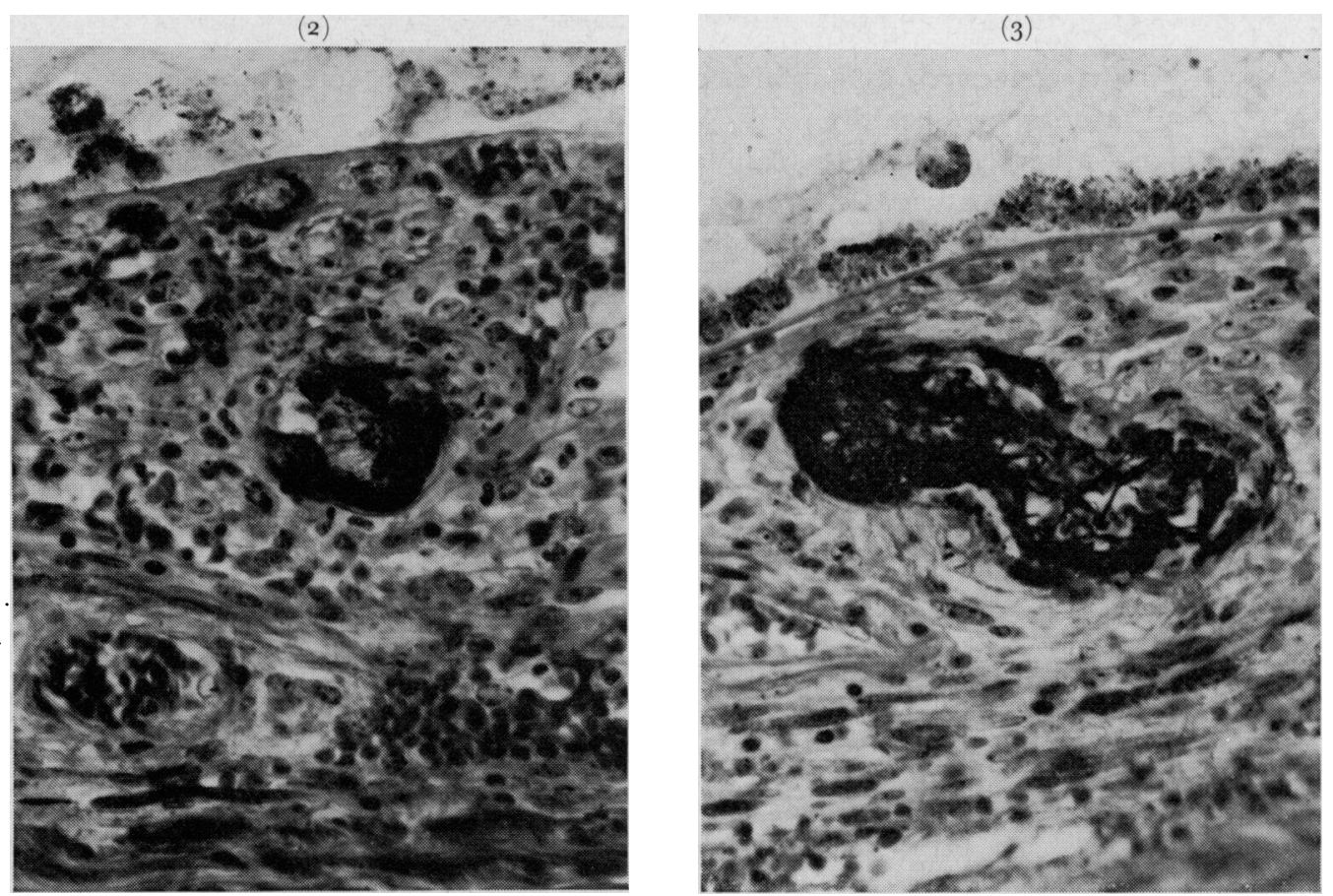

FIG. 2 High-power magnification, showing occlusive material staining heavily for fibrin in a medium-sized choroidal vessel and also in the choriocapillaris. Mallory's phosphotungstic acid haematoxylin. $\quad \times 300$

FIG. 3 High-power magnification of microangiopathy of choroid demonstrating the appearance of intraluminal fibrin strands and the absence of perivascular inflammation. Mallory's phosphotungstic acid haematoxylin. $\times 300$

allergic origin (Moore and Schoenberg, 1960; Dacie, 1967). Craig and Gitlin (1957), using fluorescein-labelled rabbit antisera against human fibrin, albumin, globulin, and platelets, have shown that the thrombi are composed largely of fibrin and not of agglutinated platelets. Furthermore, recent experimental work (Brain and others, I968) has shown that deposition of fibrin within small blood vessels may provoke haemolysis and red cell fragmentation. The secondary thrombocytopenia probably results from removal of platelets at the site of vascular damage, and their metamorphosis would be enhanced by the release of ADP and thromboplastins from the fragmenting red cells.

Pathologically, eosinophilic hyaline or slightly granular thrombi are to be found commonly in the small arterioles and capillaries of kidney, brain, myocardium, adrenals, liver, spleen, pancreas, and lymph nodes (Moschcowitz, 1925; Casale, 1965; Amorosi and Ultmann, 1966). There is an absence of perivascular infiltration by inflammatory cells, but adjacent haemorrhages are common. The latter were seen in 80 per cent. of 39 post mortem examinations of the myocardium performed by Baroldi and Manion (1967), and are considered to be related to vascular damage rather than to thrombocytopenia (Singer, 1954). Often the occlusion of vessels is incomplete or transient, and sometimes endothelial proliferation may cover the thrombus, producing a crescent-shaped lumen (Symmers, 1952).

In the case under discussion characteristic microangiopathic lesions staining heavily for fibrin were found in the choroid (Figs 1, 2, and 3), liver, kidney, myocardium, adrenal, and pancreas, though sections of the brain revealed only multiple haemorrhages. In 
Fig. 3 the appearance of fibrinous strands is well marked and it may also be noted that there is no perivascular infiltration by inflammatory cells.

The clinical ocular findings may be directly related to specific thrombotic lesions or may be symptomatic of the systemic disturbance. In the former group the following may occur:

RETINAL DETAGHMENT The detachment in the case recorded (Fig. I) was undoubtedly exudative in origin, and was most probably directly related to choroidal pathology as when exudative detachment complicates pre-eclamptic toxaemia (Gitter, Houser, Sarin, and Justice, I968) or polyarteritis nodosa (Sampson, 1945). This condition has not previously been recorded in this disease.

GHOROIDAL HAEMORRHAGE This was present microscopically in the eye sectioned adjacent to areas of microangiopathy (Fig. I).

HOMONYMOUS HEMIANOPIA This is usually caused by lesions at the occipital poles of the hemisphere (O'Brien and Sibley, I958, Case 9; Amorosi and Ultmann, 1966, Case 14). There was post mortem evidence that this may have occurred in the present case but at the time of the visual blurring it was unfortunately not possible to chart the visual fields. A feature of the cerebral microangiopathy is sometimes the absence of infarction so that the focal signs may be transient and transient hemianopias may result. In more severe cases encephalomalacia results, and in others there may be found petechial haemorrhages, usually in relation to areas of microangiopathy. In addition, some pathologists have reported the presence of cerebral oedema post mortem.

O'Brien and Sibley (1958) listed the common neurological presentations of the disease as convulsions, aphasia, cortical blindness, and an organic mental syndrome.

DIPLOPIA There may be involvement of any cranial nerve in Moschcowitz's disease, and sometimes the resulting symptoms and signs are transient. Of the seven patients described by Vassar and Spain (1953), there were three who complained of diplopia, another with an absent corneal reflex due to anaesthesia of the left side of the face, and one with right facial weakness.

ANISOCORIA An enlarged pupil on one side was found in three of the eleven patients described by O'Brien and Sibley (1958). Two patients also complained of diplopia, so that a partial palsy of the IIIrd cranial nerve is a possible explanation. Anisocoria could also be caused by progressive cerebral oedema, and there is a good description of Hutchinson's pupil in one of the cases reported by Symmers (1952).

PAPIlloedema Reports in the literature are sometimes not well documented with respect to aetiology. However, papilloedema has been reported in at least one normotensive patient by O'Brien and Sibley (1958); the patient was also suffering from headaches, nausea, and mental confusion.

RETINAL HAEMORRHAGE This was recorded in about 20 per cent. of the 27 i patients reviewed by Amorosi and Ultmann (1966); but in the absence of specific microangiopathy the cause in many cases is probably associated with renal failure. However, Moorhead ( 1966 ) raised the possibility of retinal microangiopathy in a patient with perivenous retinal haemorrhages and quoted Schaeffer and Collings (1960) as having noticed in their case sludging in the retinal arterioles. 
Eye signs that are symptomatic of the accompanying renal failure, thrombocytopenia, or haemolytic anaemia, include retinal haemorrhage (Brain and others, 1967: Case 7), papilloedema (Dunea, Muehrcke, Nakamoto, and Schwartz, I966: Case I), hypertensive retinopathy (Dacie, 1967: Case 32, and others), purpura or oedema of the lids, chemosis and subconjunctival haemorrhage (O’Brien and Sibley, I958: Case 2; Krentz and Ober, I967), and scleral icterus.

Vegetations on the heart valves occasionally occur. These were recorded in ro per cent. of the 157 cases reviewed by Casale (1965); an embolus may then be the cause of retinal vascular insufficiency as in the case described by Cahalane and Horn (1959).

\section{Summary}

A case of bilateral exudative retinal detachment is recorded for the first time in a patient $\vec{\omega}$ with Moschcowitz's disease (thrombotic thrombocytopenic purpura). The frequency of $\frac{D}{0}$. visual disturbances in the disease and the importance of early diagnosis are emphasized, and the various ocular complications are reviewed.

My very great thanks are to Dr. E. G. Rees for his advice concerning pathological material, to Dr. M. Symons for the post mortem report, to Dr. D. R. Barry for his help in photographing and reporting on the eye, to Dr. W. D. Wallace under whose care the patient was admitted, and to Mr. C. Taylor for his advice and encouragement during the preparation of this paper.

\section{References}

Allanby, K. D., hUNTSMAN, R. G., and SACker, L. S. (1966) Lancet, r, 237

Amorosi, E. L., and ultmann, J. E. (I966) Medicine (Baltimore), 45, I 39

BARoldi, G., and manion, w. c. (i967) Amer. Heart J., 74, I 73

BRAIN, M. C., BAKER, L. R. I., MGBRIDE, J. A., RUBENBERG, M. L., and DACIE, J. v. (I968) Brit. $\mathcal{J}$.

Haematol., I5, 603

cahalane, s. F., and horn, R. c. (1959) Amer. J. Med., 27, 333

CASAle, L. A. (1965) Hawaii med. J., 25, 93

Graig, J. M., and Gitlin, D. (1957) Amer. J. Path., 33, 25 I

DACIE, J. V. (I967) “The Haemolytic Anaemias", Part III, 2nd ed., pp. 854-875. Churchill,

London

DUNEA, G., muehrcke, R. G., NAKamoto, s., and schwartz, f. D. (ig66) Amer. J. Med., 41, iooo GitTer, K. A., houser, B. P., SARin, L. K., and Justice, J. (ig68) Arch. Ophthal. (Chicago), 80, 449

KRENTZ, B. E., and ObER, w. B. (1967) New York St. J. Med., 67, 702

MOORE, R. D., and SCHOENBERG, M. D. (ig6o) Blood, I5, 5I I

MOORHEAD, J. F. (1966) Arch. intern. Med., 117, 284

MOSchcowitz, E. (1925) Ibid., 36, 89

O'BRIEN, J. L., and SIBley, w. A. (I958) Neurology (Minneap.), 8, 55

SAMPSON, R. (1945) Brit. J. Ophthal., 29, 282

SCHAEFFER, W. E., and Collings, H. (I960) Guthrie Clin. Bull., 29, I8 I

SINGER, K. (1954) Advanc. intern. Med., 6, I95

SYMMERS, W. ST. C. (1952) Brit. med. J., 2, 897

VASSAR, P. S., and SPAIN, D. M. (1953) Circulation, 8, 664 